\title{
CD18-independent Neutrophil and Mononuclear Leukocyte Emigration into the Peritoneum of Rabbits
}

\author{
Robert K. Winn ** and John M. Harlan" \\ Departments of * Surgery, ${ }^{\S}$ Medicine, and ${ }^{\ddagger}$ Physiology-Biophysics, University of Washington \\ School of Medicine, Seattle, Washington 98104
}

\begin{abstract}
The CD18 mAb 60.3 and the CD49d mAb HP1 / 2 were given at the time of intraperitoneal instillation of either protease peptone or live Escherichia coli bacteria and at $12 \mathrm{~h}$. Leukocyte emigration was evaluated at 4 and $24 \mathrm{~h}$. PMN emigration $4 \mathrm{~h}$ after protease peptone instillation and injection of both $\mathrm{mAbs}$ was $10 \%$ of that in saline treatment. It was $15 \%$ of that in saline treatment after mAb 60.3 alone and unchanged by mAb HP1 / 2. At $24 \mathrm{~h}$ PMN emigration in response to protease peptone was not prevented by either CD18 or CD49d mAbs, however, when given together emigration was $10 \%$ of saline-treated animals. Mononuclear cell emigration to protease peptone was enhanced at $4 \mathrm{~h}$ by both CD18 and CD49d mAbs. The CD18 mAb did not augment mononuclear emigration in response to live bacteria. At $24 \mathrm{~h}$, neither the CD18 nor the CD49d mAb alone blocked emigration of mononuclear cells, but the combination of the two did. These studies demonstrate that: $(a)$ early (4 h) PMN emigration is CD11 / CD18 dependent; (b) late ( $24 \mathrm{~h}$ ) PMN emigration is CD11 / CD18 independent; and (c) mononuclear cells utilize the integrins CD18 and CD49d. (J. Clin. Invest. 1993. 92:1168-1173.) Key words: adhesion molecules $\bullet \beta_{1}$ and $\beta_{2}$-integrins $\bullet$ VLA-4 $\cdot$ CD49 /CD29 • CD11 /CD18
\end{abstract}

\section{Introduction}

Phagocytes must emigrate from blood to extravascular sites as part of the normal host defense and repair. A variety of inflammatory stimuli activate or up-regulate adhesion molecules on both phagocytes and endothelial cells causing them to become proadhesive (1). This results in phagocyte adherence to endothelial cells, followed by their migration along the endothelial surface to intercellular junctions, diapedesis between endothelial cells, and migration through the interstitial space to participate in the inflammatory reaction (2). During the initial stages the majority of the cells at the site of inflammation are neutrophils, but by $24-48 \mathrm{~h}$ mononuclear phagocytes predominate $(3,4)$.

Phagocyte adherence to endothelium can occur after activation of $\beta_{1}$ - and $\beta_{2}$-integrin receptors each consisting of an $\alpha$ chain noncovalently linked to a $\beta$ chain. The $\beta_{1}$ subfamily

Address reprint requests to Dr. Robert K. Winn, Department of Surgery ZA-16, Harborview Medical Center, 325 9th Avenue, Seattle, WA 98104.

Received for publication 31 December 1992 and in revised form 23 April 1993.

J. Clin. Invest.

(c) The American Society for Clinical Investigation, Inc.

0021-9738/93/09/1168/06 \$2.00

Volume 92, September 1993, 1168-1173 comprises the very late activation antigens (VLA) ${ }^{1} 1-6$ formed by the association of $\alpha_{1}$ through $\alpha_{6}$ chains (designated CD49af) with the common $\beta_{1}$ chain (CD29) as well as the alternate VLA proteins composed of $\alpha_{4} \beta_{p}$ and $\alpha_{6} \beta_{4}$ (5-7). The $\beta_{1}$-integrin receptors are broadly distributed on cells including mononuclear leukocytes and lymphocytes and are primarily involved in cell-matrix interaction. However, VLA-4 $\left(\alpha_{4} \beta_{1}\right)$ also functions in mononuclear leukocytes $(8,9)$, lymphocytes $(9-$ 11), eosinophil (11-13), and basophil (13) adherence to endothelium in vitro. Its counterstructure on endothelial cells is the cytokine-induced ligand, vascular cell adhesion molecule-1 (VCAM-1) (14).

The $\beta_{2}$ subfamily consists of three distinct $\alpha$ chains designated $\alpha_{\mathrm{L}}$ (CD11a), $\alpha_{\mathrm{M}}(\mathrm{CD} 1 \mathrm{lb})$, and $\alpha_{\mathrm{X}}$ (CD11c) associated with the common $\beta_{2}$ chain (CD18) (15). These heterodimers are found exclusively on leukocytes and mediate primarily cell-cell adhesion. Intercellular adhesion molecule-1 (ICAM1) and ICAM-2 are endothelial ligands for CD1 1a/CD18 (16, 17). ICAM-1 is also a ligand for $\operatorname{CD} 11 \mathrm{~b} / \operatorname{CD} 18(18,19)$.

The importance of $\beta_{2}$-integrins in phagocyte emigration in vivo is established by the leukocyte adhesion deficiency (LAD) syndrome, the heritable deficiency of CD11/CD18. In affected patients sites of inflammation or infection are devoid of neutrophils although some mononuclear leukocytes and eosinophils are present (20). Likewise, treatment of experimental animals with ( mAbs to CD11 /CD18 inhibits neutrophil emigration to sites of inflammation (21).

To date there have been no studies examining the relative contribution of $\beta_{1}$ - vs. $\beta_{2}$-integrins in phagocyte emigration. In this study we determined the effects of mAbs to CD18 and CD49d on neutrophil (PMN) and mononuclear leukocyte emigration into inflamed peritoneum of the rabbit.

\section{Methods}

Experimental protocol. The experimental protocols used in these experiments were reviewed and approved by the Animal Care and Use Committee of the University of Washington. These experiments conformed to the National Institutes of Health guidelines for care and use of experimental animals. New Zealand White rabbits were anesthetized, a small laparotomy was performed under sterile conditions, and $10 \mathrm{ml}$ of either a $10 \%$ solution of protease peptone or a solution containing $10^{9}$ Escherichia coli (E. coli) bacteria per milliliter was instilled into the peritoneum under direct observation. The inflammatory reaction was allowed to progress for either 4 or $24 \mathrm{~h}$, then the rabbits were killed, and peritoneal lavage was performed. Protease peptone was chosen as a general stimulus for leukocyte emigration providing a strong chemotactic signal. E. coli was chosen as a representative Gram-negative bacteria.

1. Abbreviations used in this paper: ICAM-1; intercellular adhesion molecule-1; LAD, leukocyte adhesion deficiency; VCAM-1, vascular cell adhesion molecule-1; VLA, very late activation (antigens). 
Lavage consisted of gently washing the peritoneal contents with sterile saline $(50 \mathrm{ml})$ containing heparin $(100 \mathrm{U} / \mathrm{ml})$ followed by aspiration of all available saline. Total and differential cell counts were performed on the lavage fluid to determine cell number and cell type. Animals given protease peptone were divided into four experimental groups and given the following intravenous treatment: $(a)$ saline $(n=6$ at 4 and $24 \mathrm{~h}),(b)$ the CD18 mAb $60.3(2 \mathrm{mg} / \mathrm{kg})$ alone $(n=6$ at 4 and $24 \mathrm{~h}),(c)$ the CD $49 \mathrm{~d} \mathrm{mAb} \mathrm{HPl} / 2(1 \mathrm{mg} / \mathrm{kg})$ alone $(n=6$ at $4 \mathrm{~h}$ and $n$ $=7$ at $24 \mathrm{~h})$, and $(d)$ the combination of $\mathrm{mAb} 60.3(2 \mathrm{mg} / \mathrm{kg})$ and $\mathrm{mAb} \mathrm{HPl} / 2(1 \mathrm{mg} / \mathrm{kg})(n=6$ at $4 \mathrm{~h}$ and $n=5$ at $24 \mathrm{~h})$. Animals assigned to these groups were killed at either 4 or $24 \mathrm{~h}$ after instillation of protease peptone. All animals received $\mathrm{mAb}$ at time zero $(2 \mathrm{mg} / \mathrm{kg}$, $\mathrm{CD} 18$ or $1 \mathrm{mg} / \mathrm{kg} \mathrm{CD} 49 \mathrm{~d}$ ) and those killed at $24 \mathrm{~h}$ received a second identical injections at $\sim 12 \mathrm{~h}$ later. The plasma half-life of these two mAbs is $>12 \mathrm{~h}$ (data not shown) thus the repeat dosing was every $12 \mathrm{~h}$. Animals given $E$. coli were treated with either saline $(n=9$ at $4 \mathrm{~h}$ and $n$ $=7$ at $24 \mathrm{~h}$ ) or $\mathrm{mAb} 60.3(n=7$ at $4 \mathrm{~h}$ and $n=6$ at $24 \mathrm{~h}$ ) (treatment as above) and followed for 4 or $24 \mathrm{~h}$. PMNs in the lavage fluid from the animals given bacteria were not different from those reported previously and the data have been combined (22). The timing of the peritoneal lavage was selected in order to investigate emigration expected to be dominated by PMNs $(4 \mathrm{~h})$ and a second dominated by mononuclear cells $(24 \mathrm{~h})$.

Lavage cells. Cells in the lavage fluid were counted using a hemocytometer to determine total cell number. Specific cell types were determined from differential cell counts performed on slides using Wright Giemsa stain (Diff-Quik, Baxter Healthcare Corp., McGaw Park, IL). Cell type was determined by morphologic evaluation.

Monoclonal antibodies. MAb 60.3 is a murine $\operatorname{IgG}_{2 \mathrm{a}}$ that recognizes a functional epitope on the common $\beta$ chain of the CD1 1 /CD18 glycoprotein complex (23). MAb HP1/2 is a murine $\operatorname{IgG}_{1}$ that recognizes the $\alpha$ chain of VLA-4 (CD49d) (24) and blocks the VLA-4-dependent binding of mononuclear leukocytes to Chinese hamster ovary cells transfected with cDNA of VCAM-1 (T. Carlos and J. Harlan, unpublished observations). MAb HP1/2 was a gift of Dr. R. Lobb, Biogen, Cambridge, MA. The mAbs are against human protein but recognize rabbit cells as evaluated by FACS analysis.

FACS analysis. We examined rabbit PMNs and mononuclear leukocytes prepared from whole blood using fluorescence-activated cell sorting. Blood was drawn from two rabbits at $24 \mathrm{~h}$ after instilling protease peptone into the peritoneum. One animal was given two doses of $\mathrm{mAb} 60.3$ and the other two doses of $\mathrm{mAb} \mathrm{HP1} / 2$ as described above. It was placed in a solution to lyse the red blood cells. After centrifugation, the supernatant was discarded and cells were again placed in a solution to lyse the remaining red blood cells. White blood cells were then washed in phosphate-buffered saline and resuspended in Hank's balanced salt solution. These white blood cells were incubated with mAb 60.3 , mAb HP1 /2, or a nonspecific murine IgG to evaluate surface expression of CD49d or CD18. Detection of murine mAb was performed with a goat anti-mouse-labeled antibody. Both PMNs and mononuclear leukocytes were investigated by gating on the appropriate window. Lavage cells taken at $24 \mathrm{~h}$ from the peritoneum of these animals were prepared by a similar technique.

Statistics. Difference between all of the groups was tested using the Kruskal-Wallis test for differences among means and post hoc testing using Mann-Whitney U-test with the conservative Bonferroni correction for multiple tests. The computer program StatView II was used in these computations. Differences were assumed to be statistically significant for $P<0.05$. Data are presented as mean \pm standard error.

\section{Results}

Circulating leukocytes. In normal rabbits mAb HP1 / 2 caused a slight decrease in circulating leukocytes of $<10 \%$ during the first $30 \mathrm{~min}$ after administration (data not shown). This was followed by a steady increase in leukocyte number over the next $24 \mathrm{~h}$ with mononuclear cells accounting for the majority of the increase. mAb 60.3 resulted in no acute changes in circulating leukocytes (data not shown), but did cause an increase in number of PMNs over a 24 -h period.

FACS analysis. Rabbit mononuclear cells stained positive for CD49d, and as expected the PMNs were negative. The leukocytes of the rabbit given mAb 60.3 were positive for presence of $\mathrm{mAb}$, and addition of more mAb did not alter the plot of cell number vs. fluorescence. Likewise, the leukocytes of the rabbit given $\mathrm{mAb} \mathrm{HP} 1 / 2$ were positive for $\mathrm{mAb}$, and plot of cell number vs. fluorescence was not changed with additional $\mathrm{mAb}$. These results show that mAb concentration were sufficient to saturate all of the sites on the cell surface. Lavage cells of the animal given $\mathrm{mAb} 60.3$ were also saturated with $\mathrm{mAb}$. All peritoneal cells of the rabbit given $\mathrm{mAb} \mathrm{HP} 1 / 2$ were negative for VLA-4 $\alpha$.

Lavage leukocytes (protease peptone-saline treatment). The number of mononuclear leukocytes and PMNs from animals treated with saline and having protease peptone instillation into the peritoneum are shown in Fig. 1. The baseline values were taken from identical experiments in our laboratory and reported by Mileski et al. (22). Leukocyte accumulation was similar to that observed in other inflammatory processes $(3,4,25)$. Mononuclear leukocytes in the peritoneum $4 \mathrm{~h}$ after instillation of protease peptone was $>3.5$ times greater than in normal rabbits (22) and continued to increase over the next 20 $h$ to $\sim 9.5$ times the 4-h value. PMNs in the peritoneum of normal rabbits was $\sim 7.9 \%$ of the lavage cells. PMN emigration was rapid over the first $4 \mathrm{~h}$ and exceeded the number of mononuclear leukocytes at that time but decreased over the next $20 \mathrm{~h}$ resulting in more mononuclear leukocytes than PMNs at $24 \mathrm{~h}$.

Lavage neutrophils (protease peptone-mAb treatment). The number of PMNs in lavage fluid in all four groups utilizing the normal values from Mileski et al. (22) are shown in Fig. 2. The PMNs in the peritoneal lavage fluid of saline-treated animals was described above. Lavage PMNs after mAb 60.3 treatment was significantly reduced at $4 \mathrm{~h}$ when compared with saline-treated animals $(P<0.05)$. However, mAb HP1 $/ 2$ treatment alone at this time resulted in a surprising increase in PMN accumulation compared with saline or mAb 60.3 treatment $(P<0.05)$. The combination of both $\mathrm{mAb} 60.3$ and mAb HP1/ 2 treatment resulted in almost complete block of PMN emigration $(P<0.05)$. At $24 \mathrm{~h}, \mathrm{mAb} 60.3$ treatment or

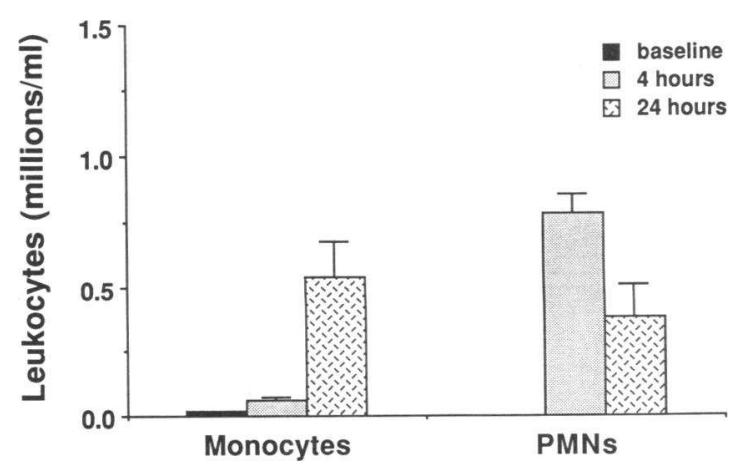

Figure 1. Leukocytes in peritoneal lavage fluid of rabbits after instillation of protease peptone. Evaluation of the lavage fluid was made at $4 \mathrm{~h}(n=6)$ and $24 \mathrm{~h}(n=6)$ after instillation and the baseline values are from normal rabbits $(n=6)$ that were reported previously reported (22). 


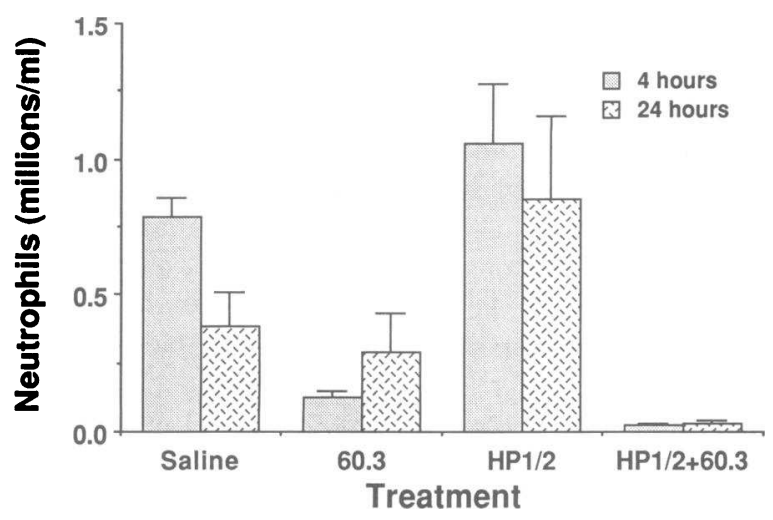

Figure 2. Neutrophils in peritoneal lavage fluid of rabbits treated with saline ( $n=6$ at 4 and $24 \mathrm{~h}$ ), the CD18 mAb 60.3 ( $n=6$ at 4 and 24 $\mathrm{h})$, the CD49d mAb HP1 $/ 2(n=6$ at $4 \mathrm{~h}$ and $n=7$ at $24 \mathrm{~h})$ or both ( $n=6$ at $4 \mathrm{~h}$ and $n=5$ at $24 \mathrm{~h}$ ). Lavage was performed at either 4 or $24 \mathrm{~h}$ after instillation of protease peptone. MAb 60.3 blocked PMN emigration at $4 \mathrm{~h}$ but not at $24 \mathrm{~h}$. MAb HP1/2 caused an increase in PMNs at $4 \mathrm{~h}$ and no change at $24 \mathrm{~h}$. The combination of mAbs effectively blocked PMN emigration.

mAb HP1/2 treatment resulted in similar PMN emigration compared with saline treatment. Notably, the combination of both $\mathrm{mAb} 60.3$ and HP1 2 resulted in almost complete block of PMN emigration at $24 \mathrm{~h}(P<0.05)$. Differences were not significant at $24 \mathrm{~h}$ between the three single-treatment groups, but the saline- and mAb HP1/2-treated groups were significantly different from the group treated with both mAbs. The difference between the mAb 60.3-treated group and those treated with both $\mathrm{mAbs}$ was not significant; however, all of the $\mathrm{mAb}$ 60.3-treated animals were greater than those receiving both mAbs.

Lavage mononuclear leukocytes (protease peptone-mAb treatment). The number of mononuclear leukocytes in lavage fluid of all four groups at $4 \mathrm{~h}$ and $24 \mathrm{~h}$ after instillation of protease peptone are shown in Fig. 3. The mononuclear leukocyte population in the peritoneum was markedly and unexpectedly increased in the animals treated with $\mathrm{mAb} 60.3$ at $4 \mathrm{~h}$ after

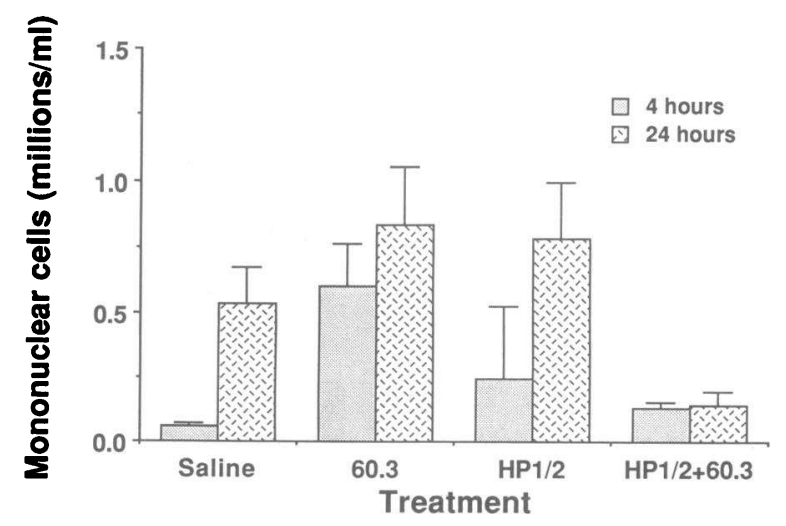

Figure 3. Mononuclear leukocytes in the lavage fluid of rabbits treated with the CD18 mAb 60.3, the CD49d mAb HP1/2 or both. Lavage was performed at either 4 or $24 \mathrm{~h}$ after instillation of protease peptone (animal number given in Fig. 2). The mAbs 60.3 and HP1/2 both caused an increase in mononuclear cell emigration by $4 \mathrm{~h}$, had little effect on emigration at $24 \mathrm{~h}$ when given individually, and significantly inhibited emigration at $24 \mathrm{~h}$ when given in combination. instillation of protease peptone compared with saline-treated animals $(P<0.05)$. Similar results were observed in one additional animal after injection of another CD18 mAb designated MHM23 (data not shown). The mean number of mononuclear leukocytes in the animals treated with mAb HP1.2 was greater (but not significantly) than the saline-treated at $4 \mathrm{~h}$. The combination of these mAbs resulted in a reduction in mononuclear cell number compared with $\mathrm{mAb} 60.3$ alone at 4 $\mathrm{h}(P<0.05)$. Treatment with either mAb 60.3 or $\mathrm{mAb} \mathrm{HP1} / 2$ alone had little or no effect on mononuclear leukocyte emigration evaluated at $24 \mathrm{~h}$ compared with saline-treated animals. The combination of the two mAbs prevented much of the mononuclear leukocyte emigration into the peritoneum compared with saline or either mAb alone. However, significance was found only for $\mathrm{mAb} 60.3 \mathrm{vs}$. both $\mathrm{mAbs}$ and not for saline or $\mathrm{mAb} \mathrm{HP} 1 / 2$ vs. both.

Lavage leukocytes (E. coli-mAb treatment). A graphical display of the emigration of leukocytes into the peritoneum in response to $E$. coli is shown in Fig. 4. Cell number $4 \mathrm{~h}$ after instillation of the $E$. coli was significantly increased with the majority being PMNs. Treatment with $\mathrm{mAb} 60.3$ resulted in a $>85 \%$ reduction in PMN emigration in response to instillation of bacteria, a result similar to that found previously (22). The CD18 mAb caused little change in the mononuclear leukocyte emigration after instillation of bacteria compared with the 10fold increase seen after instillation of protease peptone. The PMN emigration evaluated at $24 \mathrm{~h}$ following $E$. coli instillation was primarily CD18 independent as was the case with protease peptone instillation. Mononuclear leukocyte emigration, as expected, was greater at $24 \mathrm{~h}$ than at $4 \mathrm{~h}$ and was not significantly reduced when $\mathrm{CD} 18$ was blocked.

\section{Discussion}

Peripheral blood mononuclear leukocyte adherence to unstimulated and stimulated endothelium involves the $\beta_{2}$-integrin, CD11/CD18. The importance of CD11/CD18 in mononuclear leukocyte endothelial interactions is evidenced by the defect in mononuclear leukocyte emigration to skin observed in

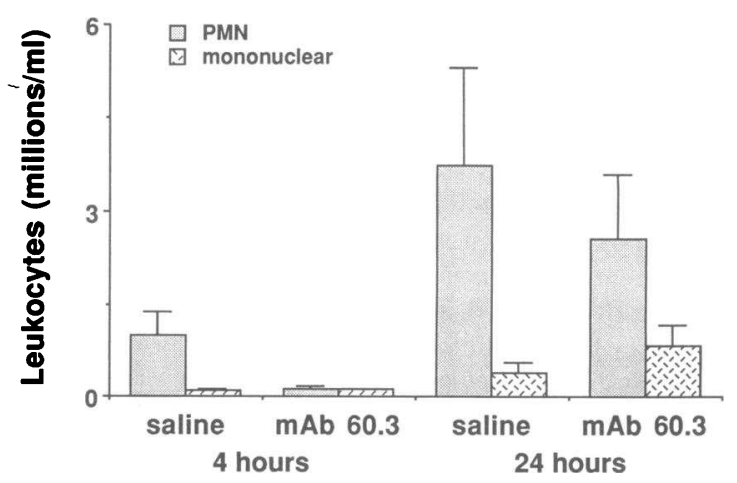

Figure 4. Mononuclear leukocytes and neutrophils in the lavage fluid of rabbits treated with saline or the CD18 mAb 60.3. Lavage was performed at $4 \mathrm{~h}(n=9$, saline; $n=7, \mathrm{mAb} 60.3,5$ of the $\mathrm{mAb} 60.3$ animals were previously reported by Mileski et al. [22]) and $24 \mathrm{~h}$ ( $n$ $=7$, saline; $n=6 \mathrm{mAb} 60.3$ ) after instillation of $E$. coli bacteria. MAb 60.3 was effective in preventing emigration at $4 \mathrm{~h}$ but had little effect at $24 \mathrm{~h}$. It had little effect on mononuclear cell emigration. 
LAD patients $(20,26,27)$ and by the ability of CD $1 \mathrm{~b}$ mAbs to reduce mononuclear leukocyte accumulation in inflamed peritoneum (28) and delayed-type hypersensitivity reactions (29).

All circulating leukocytes except neutrophils also express the $\beta_{1}$-integrin VLA-4 (CD49d/CD29). Adherence of these cell types to cytokine-activated endothelial cells in vitro involves VLA-4 binding to VCAM-1 as well as CD11/CD18 binding to ICAM-1 or $-2(8-13,15,30)$. The presence of this $\beta_{1}$-integrin on peripheral blood cell types other than neutrophils may account for the ability of mononuclear leukocytes and eosinophils but not neutrophils to traffic to sites of inflammation and immune reactions in LAD syndrome (31). Interestingly, transendothelial migration of mononuclear leukocytes $(32)$ and lymphocytes $(33,34)$ in vitro utilizes CD11/ CD18-ICAM-1 but not VLA-4-VCAM-1. However, a VLA- $4 \alpha$ mAb has been reported to inhibit lymphocyte emigration to sites of immune reaction (35), the role of VLA-4 in mononuclear leukocyte emigration has not been previously examined.

In the present study we determined the effect of CD $18 \mathrm{mAb}$ and VLA-4 $\alpha$ (CD49d) mAb given alone or in combination on neutrophil and mononuclear leukocyte emigration into inflamed peritoneum. Phagocyte accumulation was assessed at 4 and $24 \mathrm{~h}$ after instillation of protease peptone. As expected, in control animals neutrophil accumulation was markedly greater than mononuclear leukocyte accumulation at $4 \mathrm{~h}$, whereas at $24 \mathrm{~h}$ mononuclear leukocytes were the predominant cell type. We also determined the effect of CD18 and CD49d blockade on phagocyte accumulation at these two time points separately.

Administration of CD18 mAb largely prevented neutrophil accumulation at $4 \mathrm{~h}$, consistent with previous studies (36-40). The CD49d mAb which does not bind to PMNs was without effect on neutrophil emigration at $4 \mathrm{~h}$. Surprisingly, mononuclear leukocyte emigration at $4 \mathrm{~h}$ after instillation of protease peptone was greater in all three groups tested with $\mathrm{CD} 18$ or CD49d mAbs compared with saline-treated animals (although the increase was significant only in the $\mathrm{mAb}$ 60.3-treated group). There was a 10-fold increase with $\mathrm{CD} 18 \mathrm{mAb} 60.3$, 4-fold increase with the CD49d mAb, and a 2-fold increase with the combination. The total number of mononuclear leukocytes that accumulated by $24 \mathrm{~h}$ after either CD 18 or CD $49 \mathrm{~d}$ $\mathrm{mAb}$ treatment alone was somewhat greater than at $4 \mathrm{~h}$ but not significantly greater than the saline-treated group. Thus, treatment with CD18 or CD49d mAbs appears to represent an acceleration of the time course of emigration rather than an absolute increase in the number of emigrating cells. Notably, the enhanced emigration at $4 \mathrm{~h}$ was stimulus-dependent as live bacteria in the presence of $\mathrm{CD} 18 \mathrm{mAb}$ failed to promote emigration of mononuclear leukocytes in excess of that seen with saline. The mechanism of enhanced early mononuclear leukocyte accumulation after administration of CD18 or CD49d mAb and the instillation of protease peptone is unknown. It appears that the inhibition of one pathway some how facilitated the activity of the other pathway. Whether binding of CD18 or CD49d $\mathrm{mAb}$ tranduces a signal to the mononuclear leukocyte altering adhesivity of other receptor, release of proadhesive mediators, or the motile behavior of the cell remains to be determined.

The resulting emigration evaluated at $24 \mathrm{~h}$ after instillation of protease peptone with $\mathrm{CD} 18$ or CD49d blockade were somewhat different than at $4 \mathrm{~h}$. Neither the CD18 nor the CD49d
mAbs alone significantly altered mononuclear leukocyte accumulation, but in fact tended to increase mononuclear leukocyte numbers compared to saline treatment. However, the combination of CD18 and CD49d mAbs markedly inhibited mononuclear leukocyte accumulation (73\% inhibition). These results are consistent with the hypothesis that mononuclear leukocytes can utilize either CD18 or CD49d for adherence and transendothelial migration, and that, at least in this model, it is necessary to inhibit both pathways in order to produce significant inhibition of emigration. It is of note, however, that despite blockade of both CD18 and CD49d some mononuclear leukocytes still emigrated into the peritoneum (27\% of salinetreated), suggesting other adhesion pathways for emigration of these cells, e.g., selectins or yet undefined adhesion molecules.

The fact that CD18 and CD49d mAbs given alone did not block mononuclear cell emigration at $24 \mathrm{~h}$ was not due to insufficient $\mathrm{mAb}$ concentration. FACS analysis showed that all cells in the peritoneum and all circulating leukocytes were saturated with $\mathrm{mAb} 60.3$. The circulating mononuclear cells were all saturated with mAb HP1/2 and none of the cells that had emigrated into the peritoneum stained for the presence of VLA- $4 \alpha$. This suggests that as mononuclear cells differentate into tissue macrophages they loose VLA- $4 \alpha$, a result consistent with a recent report by McFeely et al. (41). In that report it was noted that alveolar macrophages do not express VLA- $4 \alpha$ on their surface.

In contrast to results at $4 \mathrm{~h}$ where the CD18 mAb alone inhibited emigration by $84 \%$, the CD18 mAb alone reduced PMN accumulation at $24 \mathrm{~h}$ by only $25 \%$. The lack of inhibition by the $\mathrm{CD} 18 \mathrm{mAb}$ was not due to insufficient antibody concentration inasmuch as both circulating leukocytes and lavage leukocytes were saturated with $\mathrm{mAb} 60.3$ in the one animal where FACS analysis was completed. Surprisingly, the combination of CD49d and CD $18 \mathrm{mAbs}$ prevented $96 \%$ of PMN emigration at $24 \mathrm{~h}$. At first glance, this increased inhibition of emigration seems inconsistent as PMNs do not have CD49d on their surface, thus mAb HP1/2 can not be acting through its effect on these cells. Emigration evaluated at $24 \mathrm{~h}$ occurs primarily through a CD18-independent pathway as demonstrated by the lack of inhibition by the CD18 mAb 60.3. We have shown CD18-independent emigration into the lung (42) and into the peritoneum after recruitment of macrophages (22). The emigration into the peritoneum was shown to occur as a result of factor(s) released by macrophages. Thus, we propose that PMN emigration in the present experiments occurs in part as a result of a factor released by macrophages. The inhibition of PMN emigration produced by the combination of $\mathrm{CD} 18$ and CD49d mAbs is thus an indirect result of blocking mononuclear leukocyte emigration into peritoneum by inhibiting CD18 and CD49d as well as direct blockade of CD18 on PMNs.

The instillation of $E$. coli bacteria resulted in a similar pattern of leukocyte emigration compared with protease peptone. At $4 \mathrm{~h}, \mathrm{PMN}$ emigration was strongly dependent on CD18 for emigration to occur with $>85 \%$ inhibition by $\mathrm{mAb} 60.3$. This was a similar reduction to that seen with protease peptone as a stimulus; however, there was no accelerated mononuclear cell emigration at $4 \mathrm{~h}$ with $E$. coli. At $24 \mathrm{~h} \mathrm{PMN} \mathrm{emigration} \mathrm{after} E$. coli, like protease peptone, was not altered by CD18 mAbs.

Administration of CD49d mAb alone resulted in a marked increase in circulating mononuclear leukocytes but not PMNs. 
Similar results were reported by Issekutz in the rat (35). Of interest, administration of CD18 mAbs produce a neutrophilic leukocytosis (40). The mechanism of CD49d mAb-induced mononuclear leukocytosis is unknown but could result from inhibition of lymphocyte recirculation or a release of leukocytes from bone marrow. This speculation comes from the demonstration that VLA4- $\alpha$ mediates lymphocyte binding to peripheral lymph nodes high endothelial venules $(43,44)$ and hematopoietic cell binding to marrow stroma (45).

Finally, although our studies demonstrate conclusively that mononuclear leukocytes utilize VLA-4 as well as CD18 in emigration to extravascular tissue, they do not necessarily indicate that the blockade is at the level of adhesion to endothelium. VLA-4 binds to the CS-1 fragment of fibronectin as well as to endothelial VCAM-1. Conceivably, inhibition of VLA-4 binding to fibronectin in the subendothelial matrix could prevent mononuclear leukocyte accumulation in the peritoneum. Additional studies with mAbs directed to endothelial ligands ICAM-1 and VCAM-1 are necessary in order to define the counterstructures for CD11/CD18 and CD49d/CD29.

\section{Acknowledgments}

We wish to thank Roy Lobb and Blake Pepinsky of Biogen Inc. for supplying and purifying the mAb HP1 2 .

This work was supported by the National Institutes of Health grants HL-43141, HL-18645, and HL-30542.

\section{References}

1. Carlos, T., and J. Harlan. 1990. Membrane proteins involved in phagocyte adherence to endothelium. Immunol. Rev. 114:5-28.

2. Allison, F., Jr., M. Smith, and W. Wood. 1955. Studies on the pathogenesis of acute inflammation. I. The inflammatory reaction to thermal injury observed in the rabbit ear champer. J. Exp. Med. 102:655-668.

3. Issekutz, A. C., and H. Z. Movat. 1980. The in vivo quantitation and kenetics of rabbit neutrophil leukocyte accumulation in the skin in response to chemotactic agents and Escherichia coli. Lab. Invest. 42:310-317.

4. Issekutz, T., A. Issekutz, and H. Movat. 1981. The in vivo quantitation and kenetics of monocyte migration into acute inflammatory tissue. Am. J. Pathol. 103:47-55.

5. Albelda, S., and C. Buck. 1990. Integrins and other cell adhesion molecules. FASEB J. 4:2868-2880.

6. Hemler, M., M. Elices, C. Parker, and Y. Takada. 1990. Structure of the integrin VLA-4 and its cell-cell and cell-matrix adhesion function. Immunol. Rev. 114:45-65.

7. Hemler, M. E. 1990. VLA proteins in the integrin family: structures, functions, and their role on leukocytes. Annu. Rev. Immunol. 8:365-400.

8. Carlos, T., N. Kovach, B. Schwartz, M. Rosa, B. Newman, E. Wayner, C. Benjamin, L. Osborn, R. Lobb, and J. Harlan. 1991. Human monocytes bind to two cytokine-induced adhesive ligands on cultured human endothelial cells: endothelial-leukocyte adhesion molecule-1 and vascular cell adhesion molecule-1. Blood. 77:2266-2271.

9. Rice, G. E., J. M. Munro, and M. P. Bevilacqua. 1990. Inducible cell adhesion molecule 110 (INCAM-110) is an endothelial receptor for lymphocytes: a CD11/CD18-independent adhesion mechanism. J. Exp. Med. 171:1369-1374.

10. Schwartz, B. R., E. A. Wayner, T. M. Carlos, H. D. Ochs, and J. M. Harlan. 1990. Identification of surface proteins mediating adherence of CD11/ CD18-deficient lymphoblastoid cells to cultured human endothelium. J. Clin. Invest. 85:2019-2022.

11. Walsh, G. M., J.-J. Mermod, A. Hartnell, A. B. Kay, and A. J. Wardlaw. 1991. Human eosinophil, but not neutrophil, adherence to IL-1-stimulated human umbilical vascular endothelial cells is $\alpha_{4} \beta_{1}$ (very late antigen-4) dependent. J. Immunol. 146:3419-3423.

12. Dobrina, A., R. Menegazzi, T. Carlos, E. Nardon, T. Cramer, J. Harlan, and P. Patriarca. 1991. Mechanisms of eosinophil adherence to cultured vascular endothelial cells. J. Clin. Invest. 88:20-26.

13. Bochner, B. S., F. W. Luscinskas, M. A. Gimbrone, W. Newman, S. A. Sterbinsky, C. P. Derse-Anthony, D. Klunk, and R. P. Schleimer. 1991. Adhesion of human basophils, eosinophils, and neutrophils to interleukin 1-activated hu- man vascular endothelial cells: contribution of endothelial cell adhesion molecules. J. Exp. Med. 173:1553-1556.

14. Elices, M. J., L. Osborn, Y. Takada, C. Crouse, S. Luhowskyj, M. Hemler, and R. R. Lobb. 1990. VCAM-1 on activated endothelium interacts with the leukocyte integrin VLA-4 at a site distinct from the VLA-4/fibronectin binding site. Cell. $60: 577-584$

15. Larson, R., and T. Springer. 1990. Structure and function of leukocyte integrins. Immunol. Rev. 114:181-217.

16. Marlin, S. D., and T. A. Springer. 1987. Purified intercellular adhesion molecule-1 (ICAM-1) is a ligand for lymphocyte function-associated antigen 1 (LFA-1). Cell. 51:813-819.

17. Simmons, D., M. W. Makgoba, and B. Seed. 1988. ICAM, an adhesion ligand of LFA-1, is homologous to the neural cell adhesion molecule NCAM. Nature (Lond.). 331:624-627.

18. Smith, C. W., R. Rothlein, B. J. Hughes, M. M. Mariscalco, H. E. Rudloff, F. C. Schmalstieg, and D. C. Anderson. 1988. Recognition of an endothelial determinant for CD18-dependent human neutrophil adherence and transendothelial migration. J. Clin. Invest. 82:1746-1756.

19. Diamond, M. S., D. E. Staunton, A. R. deFougerolles, S. A. Stacker, J. Garcia-Aguilar, M. L. Hibbs, and T. A. Springer. 1990. ICAM-1 (CD54): a counter-receptor for Mac-1 (CD11b/CD18). J. Cell Biol. 111:3129-3139.

20. Anderson, D. C., F. C. Schmalsteig, M. J. Finegold, B. J. Hughes, R. Rothlein, L. J. Miller, S. Kohl, M. F. Tosi, R. L. Jacobs, T. C. Waldrop, et al. 1985. The severe and moderate phenotypes of heritable Mac-1, LFA-1 deficiency: their quantitative defination and relation to leukocyte dysfunction and clinical features. J. Infect. Dis. 152:668-689.

21. Harlan, J. M., R. K. Winn, C. M. Doerschuk, N. B. Vedder, and C. L. Rice. 1992. In vivo models of leukocyte adherence to endothelium. In Adhesion: Its Role in Inflammatory Disease. J. M. Harlan and D. Liu, editor. W. H. Freeman \& Co., New York. 117-150.

22. Mileski, W., J. Harlan, C. Rice, and R. Winn. 1990. Streptococcus pneumoniae-stimulated macrophages induce neutrophils to emigrate by a CD18-independent mechanism of adherence. Circ. Shock. 31:259-67.

23. Beatty, P. G., J. A. Ledbetter, P. J. Martin, T. H. Price, and J. A. Hansen. 1983. Definition of a common leukocyte cell-surface antigen (Lp95-150) associated with diverse cell-mediated immune functions. J. Immunol. 131:29132918.

24. Pulido, R., M. J. Elices, M. R. Campanero, L. Osborn, S. Schiffer, A. Garcia-Pardo, R. Lobb, M. E. Hemler, and F. Sanchez-Madrid. 1991. Functional Evidence for three distinct and independently inhibitable adhesion activities mediated by the human integrin VAL-4: correlation with distinct $\alpha 4$ epitopes. $J$. Biol. Chem. 266:10241-10245.

25. Movat, H., and M. Cybulsky. 1987. Inflammation. Pathol. Immunopathol. Res. 6:153-176.

26. Bowen, T. J., H. D. Och, L. C. Altman, T. H. Price, D. E. VanEpps, D. L. Brautigan, R. E. Rosin, W. D. Perkins, B. M. Babior, S. J. Klebanoff, et al. 1982. Severe recurrent bacterial infections associated with neutrophils deficient in a cell-associated glycoprotein. J. Pediatr. 101:932-940.

27. Waldrop, T. C., D. C. Anderson, W. W. Hallmon, F. C. Schmalstieg, and R. L. Jacobs. 1986. Periodontal manisfestations of heritable Mac-1, LFA-1, deficiency syndrome: clinical, histopathologic and molecular characteristics. J. Periodontol. 58:400-416.

28. Rosen, H., and S. Gordon. 1987. Monoclonal antibody to murine type 3 complement receptor inhibits adhesion of myelomonocytic cells in vitro and inflammatory cell recruitment in vivo. $J$. Exp. Med. 166:1685-1701.

29. Rosen, H., G. Milon, and S. Gordon. 1989. Antibody to the murine type 3 complement receptor inhibits $\mathrm{T}$ lymphocyte-dependent recruitment of myelomonocytic cells in vivo. J. Exp. Med. 169:535-548.

30. Carlos, T., B. Schwartz, N. Kovach, E. Yee, M. Rosso, L. Osborn, G. Chi-Rosso, B. Newman, R. Lobb, and J. Harlan. 1990. Vascular cell adhesion molecule-1 mediates lymphocyte adherence to cytokine-activated cultured human endothelial cells. Blood. 76:965-970.

31. Schwartz, B. R., and J. M. Harlan. 1991. Consequences of deficient granulocyte-endothelium interactions. In Vascular Endothelium: Interactions with Circulating Cells. J. L. Gordon, editor. Elsevier Science Publishers, Amsterdam. 231-252.

32. Hakkert, B. C., T. W. Kuijpers, J. F. M. Leeuwenberg, J. A. vanMourik, and D. Roos. 1991. Neutrophil and monocyte adherence to and migration across monolayers of cytokine-activated endothelial cells: the contribution of CD18, ELAM-1, and VLA-4. Blood. 78:2721-2726.

33. Kavanaugh, A. F., E. Lightfoot, P. E. Lipsky, and N. OppenheimerMarks. 1991. Role of CD11/CD18 in adhesion and transendothelial migration of T Cells: analysis utilizing CD18-deficient T cell clones. J. Immunol. 146:41494156.

34. Oppenheimer-Marks, N., L. S. Davis, D. T. Bogue, J. Ramberg, and P. E. Lipsky. 1991. Differential utilization of ICAM-1 and VCAM-1 during the adhesion and transendothelial migration of human T lymphocytes. J. Immunol. 147:2913-2921. 
35. Issekutz, T. B. 1991. Inhibition of in vivo lymphocyte migration to inflammation and homing to lymphoid tissues by the TA-2 monoclonal antibody: a likely role for VLA-4 in vivo. J. Immunol. 147:4178-4184.

36. Arfors, K.-E., C. Lundberg, L. Lindbom, K. Lundberg, P. G. Beatty, and J. M. Harlan. 1987. A monoclonal antibody to the membrane glycoprotein complex CD 18 inhibits polymorphonuclear leukocyte accumulation and plasma leakage in vivo. Blood. 69:338-340.

37. Lindbom, L., C. Lundberg, J. Prieto, J. Raud, P. Nortamo, C. G. Gahmberg, and M. Patarroyo. 1990. Rabbit leukocyte adhesion molecules CD11/ $\mathrm{CD} 18$ and their participation in acute and delayed inflammatory responses and leukocyte distribution in vivo. Clin. Immunol. Immunopathol. 57:105-119.

38. Rampart, M., and T. Williams. 1988. Evidence that neutrophil accumulation induced by interleukin-1 requires both local biosynthesis and neutrophil CD18 antigen expression in vivo. Br. J. Pharmacol. 94:1143-1148.

39. Nourshargh, S., M. Rampart, P. G. Hellewell, P. J. Jose, J. M. Harlan, A. J. Edwards, and T. J. Williams. 1989. Accumulation of 111 In-neutrophils in rabbit skin in allergic and non-allergic inflammatory reactions in vivo. Inhibition by neutrophil pretreatment in vitro with a monoclonal antibody recognizing the CD18 antigen. J. Immunol. 142:3193-3198.
40. Price, T., P. G. Beatty, and S. R. Corpuz. 1987. In vivo inhibition of neutrophil function in the rabbit using monoclonal antibody to CD18. J. Immunol. 139:4174-4177.

41. McFeely, J. E., L. J. Embree, J. M. Harlan, and R. K. Albert. 1992. Expression and function of $\beta_{1}$ and $\beta_{2}$ integrins on human alveolar macrophages. Am. Rev. Respir. Dis. 145:A666. (Abstr.)

42. Doerschuk, C. M., R. K. Winn, H. O. Coxson, and J. M. Harlan. 1990. CD18-dependent and -independent mechanisms of neutrophil emigration in the pulmonary and systemic microcirculation of rabbits. J. Immunol. 144:23272333.

43. Cavender, D. E. 1990. Organ-specific and non-organ-specific lymphocyte receptors for vascular endothelium. J. Invest. Dermatol. 94:415-485.

44. Holzmann, B., and I. L. Weissman. 1989. Peyer's patch-specific lymphocyte homing receptors consist of a VLA-4-like alpha chain associated with either of two integrin beta chains, one of which is novel. EMBO (Eur. Mol. Biol. Organ.) J. 8:1735-1741.

45. Miyake, K., I. L. Weissman, J. S. Greenberger, and P. W. Kincade. 1991. Evidence for a role of the integrin VLA-4 in lympho-hemopoiesis. J. Exp. Med. 173:599-607. 